\title{
Attitudes of the American Public toward Organ Donation after Uncontrolled (Sudden) Cardiac Death
}

\author{
M. L. Volka,b,*, G. J. W. Warren ${ }^{c}$, R. R. Anspach ${ }^{d}$, \\ M. P. Couper ${ }^{b, e}$, R. M. Merion ${ }^{c, f}$ and P. A. Ubel Ub,b, $^{a, g}$ \\ a Department of Medicine, \\ ${ }^{\mathrm{b}}$ Center for Behavioral and Decision Sciences, \\ ${ }^{c}$ Department of Surgery, ${ }^{\mathrm{d}}$ Department of Sociology and \\ e Institute for Social Research, University of Michigan, \\ Ann Arbor, MI \\ ${ }^{\dagger}$ Arbor Research, Ann Arbor, MI \\ 'VA Health Services Research and Development Center \\ of Excellence, VA Ann Arbor Healthcare System, \\ Ann Arbor, MI \\ *Corresponding author: Michael L. Volk, \\ mvolk@med.umich.edu
}

Concerns about public support for organ donation after cardiac death have hindered expansion of this practice, particularly rapid organ recovery in the context of uncontrolled (sudden) cardiac death (uDCD). A nationally representative Internet-based panel was provided scenarios describing donation in the context of brain death, controlled cardiac death and uncontrolled cardiac death. Participants were randomized to receive questions about trust in the medical system before or after the rapid organ recovery scenario. Among 1631 panelists, 1049 (64\%) completed the survey. Participants expressed slightly more willingness to donate in the context of controlled and uncontrolled cardiac death than after brain death $(70 \%$ and $69 \%$ vs. $66 \%$, respectively, $p<0.01)$. Eighty percent of subjects $(95 \%$ $\mathrm{Cl}$ 77-84\%) would support having a rapid organ recovery program in their community, though $83 \%$ would require family consent or a signed donor card prior to invasive procedures for organ preservation. The idea of uDCD slightly decreased trust in the medical system from $59 \%$ expressing trust to $51 \%(p=0.02)$, but did not increase belief that a signed donor card would interfere with medical care $(28 \%$ vs. $32 \%, p=0.37)$. These findings provide support for the careful expansion of uDCD, albeit with formal consent prior to organ preservation.

Key words: Cardiac death donors, donation, public policy, transplant ethics

Received 10 September 2009, revised 27 October 2009 and accepted for publication 13 November 2009

\section{Introduction}

The supply of organs for deceased donor transplantation has reached a plateau in the United States. After rising steadily during the beginning of this decade, the overall number of organ donors has increased by less than $1 \%$ between 2006 and 2007, and in 2008 actually declined (1). This plateau has occurred despite substantial efforts over the past 10 years to increase organ donation rates, including public awareness campaigns, required request legislation, and collaborative quality improvement efforts by hospitals, organ procurement organizations (OPOs) and the Health Resources and Services Administration (HRSA) (2). The main rate-limiting step appears to be consent for donation, which is provided by only $42-54 \%$ of families of potential deceased donors (3-5).

In response to the continued organ shortage, physicians have increasingly explored the use of organs from nonstandard donors, such as those who died a cardiac death. In the past, donation after cardiac death (DCD) was performed infrequently due to poor transplantation outcomes. Recently, however, improved preservation and surgical techniques have made the use of these organs an increasingly suitable alternative (6). DCD can be classified as controlled when cardiopulmonary arrest occurs in the setting of planned withdrawal of care (Maastricht type 3), and uncontrolled when cardiopulmonary arrest occurs unexpectedly (Maastricht types 1, 2 and 4) (7).

Currently, the majority of DCD donors in the United States are controlled, and they represent less than $10 \%$ of all donors (8). Although controlled DCD (CDCD) has been rapidly increasing in recent years, the potential for continued growth is low since most controlled cardiac deaths in the hospital involve the elderly and those with comorbidities that preclude solid organ donation. Uncontrolled DCD (uDCD), on the other hand, has been recommended by the Institute of Medicine (IOM) as a promising and ethically acceptable method which could nearly triple the number of organ donors (9).

Despite endorsement by the IOM, some concerns have been expressed about the whether UDCD would be acceptable to the American public $(10,11)$. Past attempts to implement UDCD in the United States have failed in part due to negative public reactions $(12,13)$, and there is reason to believe that any reduction in public trust could lower 
rates of consent for donation even further (14). A particularly controversial aspect of UDCD involves the insertion of catheters for organ preservation prior to first person or family consent. This technique was condoned by the IOM because it enhances family autonomy to decide about donation (15). However, limited data exist measuring public attitudes regarding such details of $\operatorname{UDCD}(16,17)$. Therefore, the purpose of this study was to determine the public's willingness to donate in the settings of UDCD versus CDCD and DBD, and to explore public opinion regarding specific aspects of UDCD programs.

\section{Methods}

\section{Study design and sample}

A cross-sectional survey was conducted using a random national sample of adults age $\geq 18$ in the Knowledge Networks panel. Knowledge Networks (Menlo Park, CA) maintains an Internet survey panel designed to be representative of the entire U.S. population. The details and validity of the KnowledgePanel ${ }^{\mathrm{TM}}$ methodology have been previously described (18). Briefly, recruitment to the panel is performed using random digit dialing of listed and unlisted numbers, and computers with internet access are provided to subjects who do not already have access. Panel members are then randomly selected and contacted by e-mail to participate in individual surveys. In this survey, Black Americans were oversampled at $35 \%$ of the entire group because they are known to view organ donation less favorably than other racial groups (19). For this reason, their attitudes are particularly important when considering an uncontrolled DCD program. Otherwise, the sampling frame represented a cross-section of the entire U.S. population. This study was approved by the Institutional Review Board of the University of Michigan.

\section{Questionnaire}

The questionnaire was developed in an iterative fashion using input from multiple experts in survey design, and pilot tested on 25 participants. The overarching design was to start with relatively generic questions on organ donation, and to move toward increasingly specific scenarios. The questionnaire began with questions about willingness to donate all or some of the respondent's own organs after his/her death. Most of the items used a 6-point response scale. Both ends of the scale were labeled, but midpoints were not labeled so as to more closely approximate a continuous measure (20). These questions were then followed by items concerning willingness to donate when deciding about a family member. In order to simulate a realistic organ donation situation, participants were asked to identify their closest family member or loved one by category (spouse, child, etc.). Forty percent chose 'spouse', 27\% chose 'child', 15\% chose 'parent' and 10\% chose 'sibling'. The remainder chose 'other', and were instructed to type in their selection. This person's relationship was then referred to in subsequent questions. The following scenarios were provided to explain DBD, controlled and uncontrolled DCD. The order of scenarios \#1 and \#2 was randomly alternated to control for any possible order effects. In the UDCD scenario, extra-corporeal membrane oxygenation (ECMO) was presented as the method for organ preservation rather than cooling, since ECMO is currently the most commonly used technique worldwide (21). The term 'cardiac death' was used rather than 'circulatory determination of death' for the purposes of comprehension by the lay public.

DBD: Imagine that your [family member] was in an accident, was taken to the hospital, and placed on life support. Even though the heart is still beating, the doctors inform you that their brain is dead and will never recover. This is called brain death. How willing would you be to donate any of your [family member]'s organs in this scenario?

Controlled DCD: Imagine that your [family member] was in an accident and taken to a hospital. They were placed on life support, which means that a machine is breathing and pumping blood for them. Their brain is partially working, but they are not awake and their heart is not working well on its own. Your Ifamily memberl does not improve even after the doctors and the medical team do everything they can. The doctors tell you that your [family member] will never recover enough to come off of life support. After talking with the doctors, the decision is made to turn off the life support, and their heart stops beating. This is called cardiac death. How willing would you be to donate any of your [family member]'s organs in this scenario, after the life support has been turned off and the heart has stopped beating?

Uncontrolled DCD: Imagine that your [family member] was in an accident and is not breathing. The paramedics arrive quickly and try very hard, but they tell you your [family member] is dead. A second, totally separate, special ambulance with a medical team is alerted about the recent death. They arrive at the scene, restart $C P R$, and insert catheters, or small tubes, into blood vessels. They do this to keep blood flowing to the organs for possible donation. This is called a rapid organ recovery program, and the goal is to increase the number of available organs for donation. After all this has happened, you would then receive a call to discuss organ donation. How willing would you be to donate any of your [family member]'s organs in this situation?

Participants were also asked whether they would prefer to donate in the setting of cardiac versus brain death, whether they would support having a rapid organ recovery program where they live, and whether family consent or a signed organ donor card should be required prior to placing catheters for cardiopulmonary bypass. Finally, we hypothesized that an uncontrolled DCD program may cause people to worry that resuscitation attempts would be halted prematurely in order to procure organs for transplant. In order to test this hypothesis, we asked participants 'Do you believe that if you sign your donor card or driver's license, the paramedics or doctors will not try as hard to save your life?'(19) and 'Please indicate how much you agree or disagree with the following statement: I have trust in the medical system as a whole' (22). Participants were randomly assigned to receive this question before or after receiving the donation scenarios, to ascertain the effect of considering $\mathrm{UDCD}$ on their trust in the system.

\section{Statistical analysis and power calculations}

Demographics were compared between the groups randomized to receive the trust questions first versus the DCD scenarios first, using a t-test for normally distributed continuous data, Wilcoxon rank-sum test for skewed data, and chi-square test for categorical data. All reported questionnaire results and between-participant comparisons were adjusted for both panel sampling weights and study-specific sampling weights, including the oversampling of Black Americans. Questionnaire items with continuous measures were heavily skewed toward both ends of the scale in a bimodal distribution, so these measures were dichotomized at the midpoint for the purpose of analysis. Participants skipped $\leq 1 \%$ of questions, and missing data were treated as negative responses. Within-participant comparisons were performed using McNemar's test for paired data, and between-participant comparisons were performed using logistic regression (23). Multivariable logistic regression was used to determine independent demographic 
Public Support for uDCD

Table 1: Participant demographics $(n=1049)^{*}$

\begin{tabular}{|c|c|c|c|}
\hline & $\begin{array}{l}\text { Randomized } \\
\text { to receive } \\
\text { trust } \\
\text { scenarios } \\
\text { first }\end{array}$ & $\begin{array}{l}\text { Randomized } \\
\text { to receive } \\
\text { DCD } \\
\text { scenarios } \\
\text { first }\end{array}$ & $\begin{array}{c}\mathrm{p}- \\
\text { Value }\end{array}$ \\
\hline & $(n=543)$ & $(n=506)$ & \\
\hline Age, median (range) & $50(18-91)$ & $49(18-92)$ & 0.5 \\
\hline Gender, \% male & $46 \%$ & $50 \%$ & 0.14 \\
\hline Race or ethnicity & & & 0.03 \\
\hline White, non-Hispanic & $53 \%$ & $56 \%$ & \\
\hline Black, non-Hispanic & $38 \%$ & $32 \%$ & \\
\hline Hispanic & $4 \%$ & $8 \%$ & \\
\hline Other, non-Hispanic & $5 \%$ & $4 \%$ & \\
\hline Education & & & 0.79 \\
\hline Less than high school & $12 \%$ & $12 \%$ & \\
\hline High school & $34 \%$ & $32 \%$ & \\
\hline Some college & $26 \%$ & $29 \%$ & \\
\hline Bachelor's or higher & $28 \%$ & $27 \%$ & \\
\hline $\begin{array}{l}\text { Household income, } \\
\text { median }\end{array}$ & $\begin{array}{l}\$ 40000- \\
\$ 49999\end{array}$ & $\begin{array}{l}40000- \\
\$ 49999\end{array}$ & 0.31 \\
\hline Region & & & 0.63 \\
\hline Northeast & $20 \%$ & $18 \%$ & \\
\hline Midwest & $23 \%$ & $22 \%$ & \\
\hline South & $39 \%$ & $43 \%$ & \\
\hline West & $18 \%$ & $17 \%$ & \\
\hline
\end{tabular}

${ }^{1}$ By comparison, the U. S. Census estimates median household income for 2007 to be $\$ 50000,49 \%$ of the population to be male, and $27 \%$ of the population age 25 or higher to have a Bachelor's degree or higher (34).

predictors of willingness to donate. Power calculations were based upon detecting a $12 \%$ difference $(50 \%$ vs. $62 \%$ ) in trust in the medical system between participants randomized to receive the trust questions first versus the DCD scenarios first, for which a sample size of 374 per group was required, assuming $\beta=0.9$ and $\alpha=0.05$. All calculations were performed using Stata v. 10.0 (Statacorp, College Station, TX).

\section{Results}

Data collection began on December 18, 2008, and continued through January 13,2009 . The survey was sent to a total of 1631 panelists, and 1049 completed the survey for a response rate of $64 \%$. Participant demographics are listed in Table 1, according to whether they were randomized to receive the trust questions or DCD scenarios first.

\section{Willingness to donate}

In the overall sample, $75 \%$ (95\% $\mathrm{Cl} 71-79 \%)$ responded that they were more likely than not to donate their organs. Among those who would only donate some organs, the most common exclusions were eyes $(n=15)$, heart $(n=6)$, brain $(n=4)$, and face $(n=3)$. Consistent with previous studies (24), willingness to donate varied by racial and ethnic group with 59\% (95\% Cl 52-65\%) of Black, non-Hispanic participants expressing willingness to donate versus $81 \%$ (95\% Cl 77-86\%) among White, non-Hispanic subjects, $63 \%(95 \% \mathrm{Cl} 47-78 \%)$ among Hispanic partic-
Table 2: Predictors of willingness to donate

\begin{tabular}{lcc}
\hline & Odds ratio & $95 \% \mathrm{Cl}$ \\
\hline Age (per 10 years) & 1.02 & $0.91-1.14$ \\
Male (relative to female) & 0.87 & $0.60-1.27$ \\
Race/ethnicity & & \\
White, non-Hispanic & Reference & Reference \\
Black, non-Hispanic & $\mathbf{0 . 3 5}$ & $\mathbf{0 . 2 3}-\mathbf{0 . 5 3}$ \\
Hispanic & 0.58 & $0.28-1.21$ \\
Other, non-Hispanic & $\mathbf{0 . 2 5}$ & $\mathbf{0 . 0 9 - 0 . 6 7}$ \\
Education & & \\
Less than high school & Reference & Reference \\
High school & 1.22 & $0.70-2.13$ \\
Some college & 1.70 & $0.94-3.19$ \\
Bachelor's or higher & $\mathbf{3 . 3 5}$ & $\mathbf{1 . 6 6 - 6 . 7 6}$ \\
Household income (per \$10 K) & 1.02 & $0.97-1.07$ \\
Region & & \\
Northeast & Reference & Reference \\
Midwest & 1.49 & $0.81-2.72$ \\
South & $\mathbf{1 . 8 3}$ & $\mathbf{1 . 0 8 - 3 . 1 1}$ \\
West & 1.10 & $0.58-2.10$ \\
\hline Adjusted &
\end{tabular}

${ }^{1}$ Adjusted for sampling weights. Statistically significant results are in bold.

ipants, and 58\% (95\% Cl 33-83\%) among Other, nonHispanic participants. Participants living in the South, and those with lower levels of education were also less willing to donate, as shown by the multivariate analysis in Table 2. As hypothesized, participants were slightly less willing to donate when deciding for a family member than when deciding for themselves: $75 \%$ of participants expressed willingness to donate their own organs after their death, but only $71 \%(95 \% \mathrm{Cl} 67-76 \%)$ would agree to donate for their family member $(p=0.005)$.

\section{Donation after brain death versus cardiac death}

Participants expressed slightly more willingness to donate their family member's organs in the setting of cardiac death compared to brain death, as shown in Figure 1. In the brain death scenario, $66 \%$ indicated a willingness to donate $(95 \% \mathrm{Cl} 62-71 \%)$, compared to $70 \%(95 \% \mathrm{Cl} 66-$ $75 \%)$ and $69 \%(95 \% \mathrm{Cl} 65-73 \%)$ in the controlled and uncontrolled DCD scenarios, respectively. Although these differences were small, they were statistically significant ( $p<0.001$ for DBD vs. controlled DCD, and $p=0.004$ for DBD vs. uncontrolled DCD). There did not appear to be any interactions on willingness to donate between the type of death and race/ethnicity (data not shown). When participants were asked directly in which setting they would prefer to donate, $9 \%(95 \% \mathrm{Cl} 6-12 \%)$ chose brain death, $15 \%(95 \% \mathrm{Cl} 12-19 \%)$ chose cardiac death, 51\% (95\% Cl $46-55 \%$ ) would be equally likely to donate in either context and $25 \%(95 \% \mathrm{Cl} 21-29 \%)$ would not donate at all.

\section{Support for a rapid organ recovery program}

As shown in Table 3, participants expressed strong support for a rapid organ recovery program, with $80 \%$ (95\% Cl 77-84\%) expressing willingness to have such a program where they live. This support did not vary significantly by 


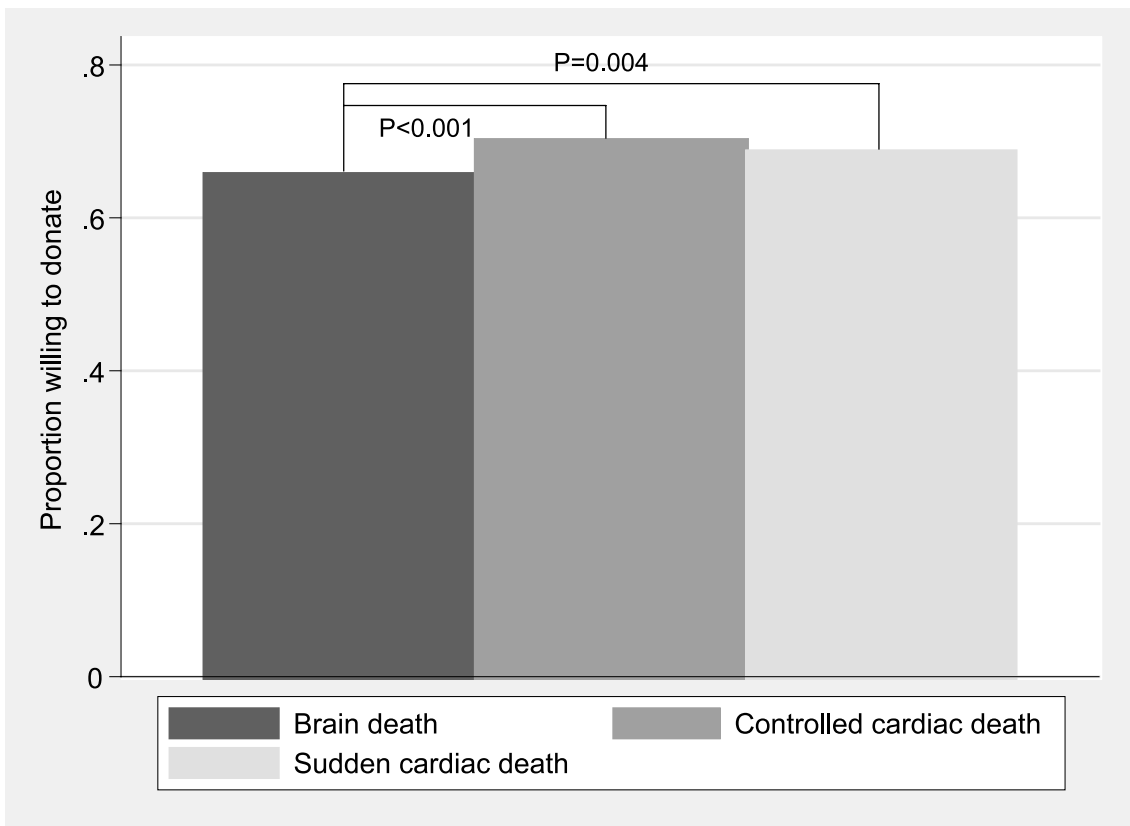

Figure 1: Proportion of Americans expressing willingness to donate the organs of their family member, in the context of brain death, controlled cardiac death and sudden (uncontrolled) cardiac death. race or ethnicity, at $81 \%(95 \% \mathrm{Cl} 77-85 \%)$ among White, non-Hispanic participants, 76\% (95\% Cl 71-81\%) among Black, non-Hispanics, 67\% (95\% Cl 52-82\%) among Hispanics and $78 \%$ (95\% Cl 58-99\%) among Other race, nonHispanic. Despite this strong support, there were some caveats. First, only $17 \%$ (95\% Cl $13-20 \%)$ of participants felt that it was appropriate for catheters to be placed for cardiopulmonary bypass prior to obtaining family consent or a signed organ donor card. Second, the idea of such a program did seem to induce feelings of mistrust in some participants. Among participants who were randomized to receive the trust question before the donation scenarios, $59 \%$ (95\% Cl 53-65\%) expressed trust in the medical system, while among those who received the questions in reverse order, only $51 \%(95 \% \mathrm{Cl} 44-57 \%)$ expressed trust

Table 3: Support for a rapid organ recovery program

\begin{tabular}{lcc}
\hline & Proportion & $95 \% \mathrm{Cl}$ \\
\hline $\begin{array}{l}\text { Willing to have a rapid organ } \\
\text { recovery program where they live }\end{array}$ & $80 \%$ & $77-84 \%$ \\
$\begin{array}{l}\text { Feel that cardiopulmonary bypass } \\
\quad \text { may be initiated prior to family }\end{array}$ & $17 \%$ & $13-20 \%$ \\
$\quad$ consent or signed donor card & & \\
Express trust in the medical system & & \\
$\quad$ Received trust questions first & $59 \%$ & $53-65 \%$ \\
$\quad$ Received DCD scenarios first & $51 \%{ }^{1}$ & $44-57 \%$ \\
Believe that signed donor card makes & & \\
$\quad$ doctors not try as hard to save life & & \\
$\quad$ Received trust questions first & $28 \%$ & $23-33 \%$ \\
$\quad$ Received DCD scenarios first & $32 \%{ }^{2}$ & $26-38 \%$ \\
\hline
\end{tabular}

${ }^{1} p=0.02$ for the difference in trust between those receiving trust versus $D C D$ questions first.

${ }^{2} p=0.37$ for the difference in this belief between those receiving trust versus DCD questions first. in the system (odds ratio $1.35, p=0.02$ ). However, the idea of a rapid organ recovery program did not significantly increase fears that signing an organ donor card would make doctors not try as hard to save their life. Among participants randomized to receive this question before the donation scenarios 28\% (95\% Cl 23-33\%) expressed belief in this idea, while among those receiving this question in reverse order $32 \%(95 \% \mathrm{Cl} 26-38 \%)$ expressed belief in this idea (odds ratio 1.19, $\mathrm{p}=0.37$ ).

\section{Discussion}

This nationwide survey demonstrates that the American public is at least as willing, if not more willing, to donate organs in the setting of cardiac death than brain death. Furthermore, the majority of people expressed strong support for a rapid recovery program to procure organs after sudden cardiac death. This support was widespread, and was not limited to Caucasians. Although we had expected that this unfamiliar form of donation would create public dismay $(10,25)$, our results instead suggest that $U D C D$ has the opportunity to gain widespread public support if it is implemented in a sensitive manner. These unexpected findings may in part reflect people's discomfort with the idea of brain death, since newspaper and television reports contain numerous inaccuracies (26) and only $34 \%$ of subjects in one single-state study believed that someone with brain death is legally dead (27). In other words, the public may prefer donation after cardiac death because it resonates more closely with popular conceptions of the dying process.

Despite this generally positive attitude, we did identify some latent concerns about donation. Participants who 
first received our donation scenarios consequently expressed less trust in the medical system than those who responded to the trust questions before learning about specific donation scenarios. Thus, while the American public has generally positive attitudes toward donation, the potential exists for implementation of UDCD to erode their trust in the medical system. These findings suggest that UDCD programs need to be conducted in a careful manner. A strict separation needs to be maintained between the medical care team and the transplantation team. Furthermore, if $\mathrm{UDCD}$ is to be performed in the United States, it should be done as part of a demonstration study which carefully investigates and reports the impact on donor families. Currently, there are federally funded studies of UDCD underway in New York and in Michigan.

Another caveat is that most participants indicated familial informed consent or a signed donor card should be required prior to insertion of catheters for organ preservation. Our study thus did not confirm the cautious support for this practice identified in prior small studies $(9,16)$. Differences between studies may relate to the method of organ preservation presented (ECMO vs. organ cooling), or may simply reflect differences in study sample size. Our results coincide with anecdotal reports from prior attempts at $\mathrm{UDCD}$ in the United States, in which families were angered by invasive procedures being performed prior to their consent (12). Clearly, obtaining rapid family consent in the setting of an unexpected cardiac arrest would pose many logistical and ethical challenges. Therefore, future uncontrolled DCD programs in the United States may be limited to those on a donor registry, or those with signed drivers licenses or organ donor cards.

Our study was limited by the fact that no sample can ever be perfectly representative of the American public. The Knowledge Networks panel excludes people without a fixed address or telephone number, and it is possible that people who agree to be in the survey panel are somehow different from other Americans. Additionally, although the response rate was reasonably good at $64 \%$, the possibility of nonresponse bias still exists. Despite these limitations, demographics of the participants in our study compare similarly to figures from the U.S. Census, as shown in Table 1. In the field of public opinion research the Knowledge Networks panel is recognized as state of the art $(28,29)$, as evidenced by publication of Knowledge Networks surveys in major journals $(18,30,31)$. In fact, several studies have demonstrated that estimates from the Knowledge Networks panel compare favorably to estimates from telephone surveys and large national faceto-face surveys such as the General Social Survey $(32,33)$. Finally, it is possible that participants in this study could have been swayed more by the wording of the specific donation scenarios than their underlying beliefs. For example, participants were not instructed that a person with brain death is legally dead, nor was the time frame between declaration of death and organ procurement specified for the DCD scenarios. Conversely, however, the inclusion of more controversial methods in the UDCD scenario (such as ECMO rather than organ cooling) may have actually biased participants against uDCD.

In conclusion, Americans do not appear to hold serious reservations about donation after cardiac death. In fact, the American public is slightly more willing to donate in the setting of cardiac death than brain death, and seems generally supportive of rapid organ recovery programs for donation in the setting of unexpected cardiac death. We believe that these findings provide support for ongoing demonstration studies of UDCD, albeit with consent obtained prior to invasive procedures for organ preservation. Such studies should include systematic analyses of the impact of uncontrolled DCD on potential donor families, especially on their trust in the medical system. For without trust, organ donation and transplantation would cease to exist entirely.

\section{Acknowledgment}

This work was supported in part by the Robert Wood Johnson Foundation and the American Gastroenterological Association (MLV). There are no conflicts of interest to report.

\section{References}

1. Tuttle-Newhall JE, Krishnan SM, Levy MF, McBride V, Orlowski JP, Sung RS. Organ donation and utilization in the United States: 1998-2007. Am J Transplant 2009; 9(4 Pt 2): 879-893.

2. Siminoff $L A$, Mercer MB. Public policy, public opinion, and consent for organ donation. Camb Q Healthc Ethics 2001; 10: 377-386.

3. Siminoff LA, Arnold RM, Caplan AL, Virnig BA, Seltzer DL. Public policy governing organ and tissue procurement in the United States. Results from the National Organ and Tissue Procurement Study. Ann Intern Med 1995; 123: 10-17.

4. Siminoff LA, Gordon N, Hewlett J, Arnold RM. Factors influencing families' consent for donation of solid organs for transplantation. JAMA 2001; 286: 71-77.

5. Sheehy E, Conrad SL, Brigham LE et al. Estimating the number of potential organ donors in the United States. N Engl J Med 2003; 349: 667-674.

6. de Vera ME, Lopez-Solis R, Dvorchik I et al. Liver transplantation using donation after cardiac death donors: Long-term follow-up from a single center. Am J Transplant 2009; 9: 773-781.

7. Abt PL, Fisher CA, Singhal AK. Donation after cardiac death in the US: History and use. J Am Coll Surg 2006; 203: 208-225.

8. OPTN. Deceased donors recovered in the U.S. by mechanism of death. 2009; Available from: http://optn.transplant. hrsa.gov/latestData/rptData.asp. Accessed October 26, 2009.

9. IOM. Organ Donation: Opportunities for Action. Washington D.C.: National Academies Press, 2006.

10. Stein RNY. Planning special ambulance to recover organs. Washington Post 2008 Saturday, May 28

11. Childress JF. Organ donation after circulatory determination of death: Lessons and unresolved controversies. J Law Med Ethics 2008; 36: 766-771, 610 


\section{Volk et al.}

12. Light JA. The Washington, D.C. experience with uncontrolled donation after circulatory determination of death: Promises and pitfalls. J Law Med Ethics 2008; 36: 735-740, 610.

13. Koughan F, Bogdanich W. Response to "From Pittsburgh to Cleveland: NHBD Controversies and Bioethics" by George J. Agich (CO Vol 8, No 3). Camb Q Healthc Ethics 1999; 8: 514-523.

14. Boulware LE, Troll MU, Wang NY, Powe NR. Perceived transparency and fairness of the organ allocation system and willingness to donate organs: A National Study. Am J Transplant 2007; 7: 1778-1787.

15. DuBois JM. Increasing rates of organ donation: Exploring the Institute of Medicine's boldest recommendation. J Clin Ethics 2009; 20: $13-22$.

16. Dubois JM, Waterman AD, Iltis A, Anderson J. Is rapid organ recovery a good idea? An exploratory study of the public's knowledge and attitudes. Am J Transplant 2009; 9: 1-8.

17. Seltzer DL, Arnold RM, Siminoff LA. Are non-heart-beating cadaver donors acceptable to the public? J Clin Ethics 2000; 11: $347-$ 357.

18. Baker L, Wagner TH, Singer S, Bundorf MK. Use of the Internet and e-mail for health care information: Results from a national survey. JAMA 2003; 289: 2400-2406.

19. Siminoff LA, Burant CJ, Ibrahim SA. Racial disparities in preferences and perceptions regarding organ donation. J Gen Intern Med 2006; 21: 995-1000.

20. Zikmund-Fisher BJ, Smith DM, Ubel PA, Fagerlin A. Validation of the subjective numeracy scale: Effects of low numeracy on comprehension of risk communications and utility elicitations. Med Decis Making 2007; 27: 663-671.

21. Jimenez-Galanes S, Meneu-Diaz MJ, Elola-Olaso AM et al. Liver transplantation using uncontrolled non-heart-beating donors under normothermic extracorporeal membrane oxygenation. Liver Transpl 2009; 15: 1110-1118.
22. Hall MA. Researching medical trust in the United States. J Health Organ Manage 2006; 20: 456-467.

23. Rosner B. Fundamentals of biostatistics. 6th Ed. Belmont, CA: Thomson-Brooks/Cole, 2006.

24. Gallup. National Survey of Organ and Tissue Donation Behaviors and Attitudes. 2005. Available from: http://www.organdonor. gov/survey2005/introduction.shtm. Accessed February 23, 2009.

25. D'Alessandro AM, Peltier JW, Phelps JE. An empirical examination of the antecedents of the acceptance of donation after cardiac death by health care professionals. Am J Transplant 2008; 8: 193200.

26. Morgan SE, Harrison TR, Chewning L, Davis L, Dicorcia M. Entertainment (mis)education: The framing of organ donation in entertainment television. Health Commun 2007; 22: 143-151.

27. Siminoff LA, Burant C, Youngner SJ. Death and organ procurement: Public beliefs and attitudes. Kennedy Inst Ethics J 2004; 14: 217-234.

28. Couper M. Web surveys: A review of issues and approaches. Public Opin Q 2000; 64: 464-494.

29. Kreuter F, Presser S, Tourangeau R. Social desirability Bias in CATI, IVR, and web surveys. Public Opin Q 2008; 72: 847-865.

30. Silver RC, Holman EA, McIntosh DN, Poulin M, Gil-Rivas V. Nationwide longitudinal study of psychological responses to September 11. JAMA 2002; 288: 1235-1244.

31. Miller JD, Scott EC, Okamoto S. Science communication. Public acceptance of evolution. Science 2006; 313: 765-766.

32. Berrens RP, Bohara AK, Jenkins-Smith H, Silva C, Weimer DL. The advent of internet surveys for political research: A comparison of telephone and internet samples. Polit Anal 2003; 11: 1-22.

33. Smith TW. An experimental comparison of knowledge networks and the GSS. Int J Public Opin Res 2003; 15: 167-179.

34. 2000 United States Census. 2000. Available from: http://www. census.gov/. Accessed February 26, 2009. 